\title{
Effects of in ovo injection of lysine and methionine into fertile broiler (parent stock) eggs on hatchability, growth performance, caecum microbiota, and ileum histomorphology
}

\author{
Isa Coskun ${ }^{1 *}$, Aysenur Akkan ${ }^{1}$, Guray Erener ${ }^{2}$ \\ ${ }^{1}$ Ahi Evran University, Faculty of Agriculture, Department of Animal Science, Kirsehir, Turkey. \\ 2 Ondokuz Mayis University, Faculty of Agriculture, Department of Animal Science, Samsun, Turkey.
}

\begin{abstract}
We investigated the effect of in ovo injection of lysine, methionine, or their mixture into fertile broiler eggs on hatchability, chick weight, growth performance, inner organ development, caecum total aerobic bacteria, E. coli, coliforms, Enterobactericaea, and ileal histomorphology of broilers. Three hundred fertile eggs obtained from 60-week-old Ross 308 broiler breeders were used. Before this study, a preliminary study was conducted to determine the optimal amino acid dose. Optimum amino acid dose was determined as $2 \mathrm{mg} / 0.2 \mathrm{~mL}$. Before replacing hatching machine, eggs were weighed individually and numbered. On day 16 of incubation, these eggs were allocated to treatment groups: negative control (no injection), positive control (distilled water injection $0.2 \mathrm{~mL}$ ), lysine $(2 \mathrm{mg} / 0.2 \mathrm{~mL})$, methionine $(2 \mathrm{mg} / 0.2 \mathrm{~mL})$, and lysine + methionine $(1+$ $1 \mathrm{mg} / 0.2 \mathrm{~mL}$ ). The hatching window lasted $32 \mathrm{~h}$. During hatching, chicks hatched in the first hour and the last $6 \mathrm{~h}$ were discarded from the study to ensure equal hatching time. After hatching, 120 one-day-old healthy chicks were divided into five treatment groups with three replicates, each including eight birds, for 21 days. These chicks were given a starter diet (3080 kcal/ $\mathrm{kg}$ metabolizable energy and $22 \%$ crude protein) during the trial. The results showed that in ovo injection of lysine, methionine, and lysine + methionine did not affect relative chick weight, livability, growth performance, caecum microbiota, and ileal villi length and thickness. Lysine injection increased hatchability compared with the negative control and methionine-injected groups. Gastrointestinal weight increased in lysine-injected group compared with the negative control group. The in ovo injection of $2 \mathrm{mg} / 0.2 \mathrm{~mL}$ lysine have a positive effect on the hatchability of fertile eggs.
\end{abstract}

Key Words: amino acid, broiler chick, in ovo feeding, poultry, Ross 308

\section{Introduction}

It has been reported that chick growth can be increased with in ovo nutrition (Ferket, 2006). Although the development of digestive tracts, digestion capacity and digestion of nutrients, subsequent feed conversion ratio, skeletal muscle development, and breast meat yield can be improved, skeletal system disorders, diseases, and deaths can be reduced by in ovo nutrient feeding on days 16, 17, and 18 of incubation (Uni et al., 2003; Tako et al., 2004; Foye et al., 2006). Avian embryos grow bigger at the late term of incubation, so the nutrient requirement of embryos increases in egg, and nutrients of eggs are finite. Avian embryos use these finite nutrients and amino acids in eggs

Received: October 17, 2017

Accepted: December 12, 2017

*Corresponding author: isa.coskun@ahievran.edu.tr

Copyright (C) 2018 Sociedade Brasileira de Zootecnia. This is an Open Access article distributed under the terms of the Creative Commons Attribution License (http://creativecommons.org/licenses/by/4.0/), which permits unrestricted use, distribution, and reproduction in any medium, provided the original work is properly cited. to provide tissue growing at the late term of incubation. Ohta et al. (1999) reported that the amount of essential and non-essential amino acids have not been enough for embryonic protein synthesis, accretion, and, consequently, muscle production. For this reason, exogenous amino acids should be applied to eggs in ovo (Uni and Ferket, 2004; Ferket, 2006; Ebrahimi et al., 2017), especially lysine and methionine, which are the essential amino acids for poultry. Ohta et al. (1999) showed that the lysine and methionine concentrations in the blood plasma and tissue of newly hatched control chicks were lower than those of chicks that received amino acid mix in ovo. It was reported that in ovo injections of lysine and methionine increased nutrient digestibility by increasing ileum villi surface area (Tako et al., 2005), increasing hatching weight (Bhanja and Mandal, 2005), and increasing final weight in broiler chicks (Bhanja et al., 2012).

Previous in ovo feeding studies showed that injection volume (Zhai et al., 2011) and injection site (Ohta et al., 2001; Khaligh et al., 2017) had important effects on hatchability rate. Khaligh et al. (2017) reported that injection should 
not be too deep to avoid embryo injuries. In addition, Ebrahimnezhad et al. (2011) stated that $0.5 \mathrm{~mL}$ in ovo injection into amniotic fluid caused an allergic cavity, stoppage in breathing, and embryonic death due to increase in osmotic pressure in eggs (Bhanja and Mandal, 2005). On the contrary, in ovo injection of 1 and $0.5 \mathrm{~mL}$ amino acid into the albumen performed by Bhanja et al. (2012) and Gaafar et al. (2013), respectively, did not affect hatchability rate. The above studies showed that there is still a need for further investigation of in ovo amino acid injections to find a more appropriate volume and injection dose. Also, the effects of low-dose amino acid injection on the air sac of eggs are not known. Therefore, the current study was carried out to determine the effects of the in ovo injection of low-dose $(2 \mathrm{mg} / 0.2 \mathrm{~mL})$ lysine, methionine, and lysine + methionine into the air sac of fertile eggs on hatchability, growth of 21-day-old chicks, as well as caecum microbiota and ileum histomorphology of broiler chicks.

\section{Material and Methods}

The experiment was conducted in Kirsehir, Turkey (39 $9^{\prime} 45.8736^{\prime \prime}$ S, 34 $\left.4^{\circ} 9^{\prime} 34.2000^{\prime \prime} \mathrm{W}\right)$. The current experimental protocol was approved by the local Animal Care and Use Committee (case no. 11.07.2013/01/1).

In this study, fertile broiler eggs (400) of Ross 308 breeder flock (60 weeks of age) were obtained from a commercial hatchery. To form an air gap, eggs were incubated for two days at $25{ }^{\circ} \mathrm{C}$. Afterwards, eggs were weighed individually; abnormally weighted eggs were discarded from the experiment, and 300 eggs were incubated under standard conditions $\left(37.8{ }^{\circ} \mathrm{C}\right.$ and $60 \%$ relative humidity). Non-fertile eggs were discarded from the incubator at the 12th day of incubation, and 238 fertile eggs were distributed into five different treatment groups with three replicates, each including 16 eggs according to the basis of equal egg weight. One replicate of lysine group included 14 eggs only. Treatment groups were negative control (no injection), positive control (distilled water), lysine, methionine, and lysine + methionine. On day 16 of incubation, the blunt side of the egg was sterilized with $70 \%$ ethanol. After that, the in ovo administration of lysine, methionine, and their mixture at $0.2 \mathrm{~mL}$ per egg was applied through the air sac of the eggs using a 21-gauge needle. Lysine $(10.5 \mathrm{~g} / 1000 \mathrm{~mL})$, methionine $(10.5 \mathrm{~g} / 1000 \mathrm{~mL})$, and lysine + methionine $(5.25$ lysine +5.25 methionine $\mathrm{g} / 1000$ $\mathrm{mL}$ ) were diluted in a vehicle solution generated with $0.5 \%$ $\mathrm{NaCl}$. Two milligrams of amino acid was applied with $0.2 \mathrm{~mL}$ vehicle solution per egg. After injection, holes were sealed with adhesive tape and incubation continued. After injection, eggs were allocated to different treatment groups. Chick weight after hatching was determined by using an electronic scale $(0.01 \mathrm{~g}$ sensitivity) $6 \mathrm{~h}$ after hatching (Coskun et al., 2014). In this study, five treatment groups with three replicates were used. A total of 120 one-day-old healthy chicks were allocated to five treatment groups. Each treatment group included 24 chicks, and each replicate included eight chicks (four male and four female). Chicks were reared in compact-type battery cages and placed in an environmentally controlled room with windows.

All groups were fed ad libitum with a commercial broiler starter diet (Table 1). Synthetic lysine and methionine were used in this study. Lysine included $78.5 \%$ lysine monohydrochloride. Methionine included $88 \%$ methionine. Feed and drinking water were offered ad libitum. Feed intake and body weight per cage were calculated weekly. Two birds (one female and one male) from each cage with near to average weight (six birds per treatment) were slaughtered at 21 days of age. The weights of the heart, liver, gizzard, pancreas, bursa of Fabricius, proventriculus, and whole gut and the length of the whole gut were determined. The whole gut and the organs were carefully excised. Weight ( $\mathrm{g} / 100 \mathrm{~g}$ body weight) and length of the gut ( $\mathrm{cm} / 100 \mathrm{~g}$ body weight) were expressed as a portion of body weight. Caecum contents $(1 \mathrm{~g})$ for microbiological enumeration were transferred into dilution bottles. Anaerobic diluents were added to

Table 1 - Composition of the experimental diet

\begin{tabular}{lc}
\hline Item & $\mathrm{g} / \mathrm{kg}$ as fed \\
\hline Maize & 440.0 \\
Soybean meal (44\%) & 411.5 \\
Meat and bone meal (45\%) & 40.0 \\
Soybean oil & 65.0 \\
Dicalcium phosphate & 25.0 \\
L-lysine HCl & 7.0 \\
DL-methionine & 3.5 \\
NaCL & 3.0 \\
Vitamin premix ${ }^{1}$ & 2.5 \\
Mineral premix ${ }^{2}$ & 2.5 \\
Analyzed nutrient composition & \\
Metabolizable energy (kcal/kg) & 3080 \\
Crude protein (\%) & 22.39 \\
Crude fiber (\%) & 2.80 \\
Crude fat (\%) & 8.50 \\
Calcium (\%) & 7.60 \\
Available phosphorus (\%) & 3.80 \\
\hline
\end{tabular}

${ }^{1}$ Premix provided per kg of diet: vitamin A, 12,000 IU; vitamin D3, 2,400 IU; vitamin E, $30 \mathrm{mg}$; vitamin K3, 4 mg; vitamin B1, 3 mg; vitamin B2, $7 \mathrm{mg}$; vitamin B6, $5 \mathrm{mg}$; vitamin B12, $15 \mu \mathrm{g}$; niacin, $25 \mathrm{mg}$.

${ }^{2}$ Premix provided per kg of diet: Fe, $80 \mathrm{mg}$; folic acid, $1 \mathrm{mg}$; pantothenic acid, $10 \mathrm{mg}$; biotin, $45 \mathrm{mg}$; choline, $125,000 \mathrm{mg}$; $\mathrm{Cu}, 5 \mathrm{mg}$; $\mathrm{Mn}, 80 \mathrm{mg}$; Zn, $60 \mathrm{mg}$; Se, $150 \mu \mathrm{g}$. 
achieve a 1:10 (w/v) dilution. Caecum contents were vortexed until completely homogenized and distributed using standard methods into a 1:10 (v/v) dilution series of tubes containing anaerobic peptone buffer. Appropriate dilutions were inoculated onto the plates. Total aerobic bacteria, Escherichia coli, coliform, and Enterobactericaea count in caecal samples were determined by using $3 \mathrm{M}$ Petrifilm TM (3M Microbiology Products St. Paul MN 55114 USA). The following manufacturer's instructions for incubation conditions were used to determine the microbial counts of samples: total aerobic bacteria, at $32{ }^{\circ} \mathrm{C}$ for $48 \mathrm{~h}$; Escherichia coli, at $32^{\circ} \mathrm{C}$ for $24 \mathrm{~h}$; coliform, at $35^{\circ} \mathrm{C}$ for $24 \mathrm{~h}$; and Enterobactericaea, at $32{ }^{\circ} \mathrm{C}$ for $24 \mathrm{~h}$. Escherichia coli, coliform, and Enterobactericaea colonies were counted, and the average number of live bacteria was calculated based on per gram of original caecal contents as $\log 10 \mathrm{cfu} / \mathrm{g}$.

Ileum samples were cut into $1.0-\mathrm{cm}$ pieces and placed into $10 \%$ formalin for histomorphological processing. Tissue sections were inserted into tissue cassettes. After the dehydration process, tissue sections were embedded in paraffin blocks, cut to $5-\mu$ thickness, and placed on a slide. Each sample of duodenum histomorphological tissue was prepared and stained with hematoxylin and eosin solution by using standard paraffin-embedding methods. After the embedding process, duodenum villi length and duodenum width were evaluated by using an image processing and analysis system (ZEN 2012 SP2) for Zeiss Primo Star HD Light Microscope.

The data were analysed using the ANOVA procedure of SPSS software (Windows version of SPSS, release 15.00). Differences between group means were separated by Duncan's multiple range tests.

\section{Results}

No mortality was observed in this study. Hatchability rate increased more in the lysine group than in the negative control and methionine groups $(\mathrm{P}<0.05)$ (Table 2$)$. Relative chick weight was not changed by any injections $(\mathrm{P}>0.05)$.
Live weight gain, feed intake, and feed conversion ratio were not different among the groups (Table 3). Heart, gizzard, gastrointestinal length, and bursa of Fabricius weight were not changed by treatments, while liver weight was increased more in the methionine group than in the negative and positive control groups (Table 4). Gastrointestinal weight in the lysine group was higher than in the negative control group. Proventriculus weight was higher in the lysine group than in the positive control group $(\mathrm{P}<0.05)$. Pancreas weight was increased by lysine and methionine treatments compared with the positive control treatment. Villi length, villi width, and crypt depth were not different among groups (Table 5). Total aerobic bacteria, E. coli, Enterobactericaea, and coliforms were not changed by treatment groups (Table 6).

\section{Discussion}

The results of this study showed that in ovo injection of lysine, methionine, and lysine + methionine had no negative effects on performance parameters; above all, in ovo injection of lysine into the air sac of fertile eggs increased hatchability. Different results about performance parameters have been obtained from different previous in ovo injection studies. For example, Al Daraji et al. (2012), Bhanja et al. (2004), and Keralapurath et al. (2010) reported that in ovo amino acid included lysine, and that methionine injection did not affect growth performance of birds. On the other hand, Foye et al. (2006), Kadam et al. (2008), Gaafar et al. (2013), and Shafey et al. (2014) reported that in ovo amino acid injection increased the growth performance of broilers. The earlier studies showed that nutrient injection volume, injection time, and injection depth might affect the growth performance parameters of broilers. In the current study, $0.2 \mathrm{~mL}$ of in ovo injection carried out on the 16th day of incubation into the air sac of eggs did not decrease hatchability. At the end of this study, performance parameters were not changed since there might not have been the presence of any stress factors during the experimental period for chicks.

Table 2 - Effects of in ovo injection of lysine, methionine, and lysine + methionine on hatchability and relative chick weight of broiler chicks

\begin{tabular}{|c|c|c|c|c|c|c|}
\hline & Negative control & Positive control & Methionine & Lysine & Lysine + methionine & SEM \\
\hline Number & 48 & 48 & 48 & 46 & 48 & \\
\hline Hatchability (\%) & $70.83 a$ & $79.17 \mathrm{ab}$ & $77.08 \mathrm{a}$ & $89.13 b$ & $81.25 \mathrm{ab}$ & 2.07 \\
\hline Relative chick weight (\%) & 68.89 & 69.53 & 69.85 & 70.20 & 71.23 & 1.85 \\
\hline
\end{tabular}

Negative control = no injection; positive control = injection of $0.2 \mathrm{~mL}$ distilled water; methionine $=2 \mathrm{mg} / 0.2 \mathrm{~mL} ; \mathrm{lysine}=2 \mathrm{mg} / 0.2 \mathrm{~mL} ; \mathrm{and}$ lysine $+\mathrm{methionine}=1+1 \mathrm{mg} / 0.2 \mathrm{~mL}$. SEM - standard error of mean.

$\mathrm{a}-\mathrm{b}$ - Means for the same treatment and effect or with different letter differ significantly respectively $(\mathrm{P}<0.05)$ 
Although there was no significant difference between the low dose $(2 \mathrm{mg} / 0.2 \mathrm{~mL})$ of lysine, methionine, and lysine + methionine injection, the relative chick weight tended to increase by all injections. In our earlier study, we found that the injection of methionine $(50 \mathrm{mg} / 1 \mathrm{~mL})$ into the amnion of eggs increased relative chick weight from 70 to $73 \%$, but decreased hatchability by about $5 \%$ compared with the control group (Coskun et al., 2014). This result showed that injection volume has an important effect on hatchability. It has been reported that the injection volume (Ferket et al., 2005) and injection site (Ohta et al., 2001) have important effects on hatchability rate. In addition, Zhai et al. (2011) reported that hatchability rate decreases when injection volume increases. Ebrahimnezhad et al. (2011) reported that $0.5 \mathrm{~mL}$ in ovo injection into the amniotic fluid caused an allergic cavity, stoppage of breathing, and embryonic death due to increase in osmotic pressure in eggs. In the current study, $2 \mathrm{mg} / 0.2 \mathrm{~mL}$ in ovo injection of lysine increased hatchability without affecting relative chick weight. Similarly, $0.1 \mathrm{~mL}$ in ovo injection of lysine + methionine increased hatchability without affecting relative chick weight (Al-Shamery and Al-Shuhaib, 2015). Ileum histomorphological parameters might not have been affected by low-dose lysine and methionine injection into the air sac of eggs. In contrast, Ebrahimi et al. (2017) reported that injection of 10 and $20 \mathrm{mg}$ L-lysine into

Table 3 - Effects of in ovo injection of lysine, methionine, and lysine + methionine on live weight, feed intake, and feed conversion ratio of broiler chicks

\begin{tabular}{lcccccc}
\hline & Negative control & Positive control & Methionine & Lysine & Lysine + methionine & SEM \\
\hline Live weight gain $(\mathrm{g})$ & 703.46 & 654.24 & 701.24 & 691.46 & 664.25 & 9.066 \\
Feed intake $(\mathrm{g})$ & 1036.21 & 971.00 & 1056.30 & 1040.81 & 980.47 & 14.93 \\
Feed conversion ratio $(\mathrm{g} / \mathrm{g})$ & 1.47 & 1.48 & 1.51 & 1.51 & 1.48 & 0.012 \\
\hline
\end{tabular}

Negative control $=$ no injection; positive control $=$ injection of $0.2 \mathrm{~mL}$ distilled water; methionine $=2 \mathrm{mg} / 0.2 \mathrm{~mL} ; \mathrm{lysine}=2 \mathrm{mg} / 0.2 \mathrm{~mL} ;$ and lysine $+\mathrm{methionine}=1+1 \mathrm{mg} / 0.2 \mathrm{~mL}$. SEM - standard error of mean.

Table 4 - Effects of in ovo injection of lysine, methionine, and lysine + methionine on inner organ development (cm, g/100 g LW)

\begin{tabular}{|c|c|c|c|c|c|c|}
\hline & Negative control & Positive control & Methionine & Lysine & Lysine + methionine & SEM \\
\hline Heart & 0.59 & 0.64 & 0.60 & 0.63 & 0.61 & 0.013 \\
\hline Liver & $3.02 \mathrm{a}$ & $3.01 \mathrm{a}$ & $3.48 \mathrm{~b}$ & $3.15 \mathrm{ab}$ & $3.10 \mathrm{ab}$ & 0.063 \\
\hline Gizzard & 2.21 & 2.11 & 2.07 & 2.2 & 2.13 & 0.044 \\
\hline Pancreas & $0.41 \mathrm{ab}$ & $0.37 \mathrm{a}$ & $0.44 \mathrm{~b}$ & $0.44 \mathrm{~b}$ & $0.39 \mathrm{ab}$ & 0.011 \\
\hline GITW & $20.69 \mathrm{a}$ & $22.23 \mathrm{ab}$ & $22.51 \mathrm{ab}$ & $24.72 b$ & $22.49 a b$ & 0.410 \\
\hline GITL & 6.40 & 6.38 & 6.41 & 6.07 & 5.95 & 0.150 \\
\hline Bursa of fabricius & 0.23 & 0.24 & 0.27 & 0.25 & 0.25 & 0.009 \\
\hline Proventriculus & $0.59 \mathrm{ab}$ & $0.54 \mathrm{a}$ & $0.67 \mathrm{ab}$ & $0.70 \mathrm{~b}$ & $0.61 \mathrm{ab}$ & 0.019 \\
\hline
\end{tabular}

Negative control = no injection; positive control = injection of $0.2 \mathrm{~mL}$ distilled water; methionine $=2 \mathrm{mg} / 0.2 \mathrm{~mL} ; \mathrm{lysine}=2 \mathrm{mg} / 0.2 \mathrm{~mL} ; \mathrm{and}$ lysine $+\mathrm{methionine}=1+1 \mathrm{mg} / 0.2 \mathrm{~mL}$. LW - live weight; GITW - gastrointestinal tract weight (g/100 g LW); GITL - gastrointestinal tract length (cm/100 g LW); SEM - standard error of mean.

$\mathrm{a}-\mathrm{b}$ - Means for the same treatment and effect with different letters differ significantly $(\mathrm{P}<0.05)$

Table 5 - Effect of in ovo injection of lysine, methionine, and lysine + methionine on ileum histology

\begin{tabular}{lcccccc}
\hline & Negative control & Positive control & Methionine & Lysine & Lysine + methionine & SEM \\
\hline Villi length $(\mu \mathrm{m})$ & 1140.71 & 1123.30 & 1128.45 & 1151.12 & 1201.05 & 11.07 \\
Villi width $(\mu \mathrm{m})$ & 234.57 & 223.22 & 248.26 & 230.36 & 240.45 & 9.58 \\
Crypt depth $(\mu \mathrm{m})$ & 152.41 & 165.28 & 174.58 & 154.71 & 186.79 & 9.01 \\
\hline
\end{tabular}

Negative control = no injection; positive control = injection of $0.2 \mathrm{~mL}$ distilled water; methionine $=2 \mathrm{mg} / 0.2 \mathrm{~mL} ;$ lysine $=2 \mathrm{mg} / 0.2 \mathrm{~mL} ; \mathrm{and}$ lysine $+\mathrm{methionine}=1+1 \mathrm{mg} / 0.2 \mathrm{~mL}$. SEM - standard error of the mean.

Table 6 - Effect of in ovo injection of lysine, methionine, and lysine + methionine on caecum microbiota $\left(\log _{10} \mathrm{cfu} \mathrm{g}^{-1}\right)$

\begin{tabular}{lcccccc}
\hline & Negative control & Positive control & Methionine & Lysine & Lysine + methionine & SEM \\
\hline Total aerobic bacteria & 1.32 & 1.27 & 1.29 & 1.35 & 1.30 & 0.017 \\
E. coli & 2.16 & 2.19 & 2.18 & 2.20 & 2.15 & 0.007 \\
Enterobacter & 2.10 & 2.11 & 2.06 & 2.09 & 2.09 & 0.008 \\
Coliform & 2.11 & 2.09 & 2.10 & 2.13 & 2.12 & 0.010 \\
\hline
\end{tabular}

Negative control = no injection; positive control $=$ injection of $0.2 \mathrm{~mL}$ distilled water; methionine $=2 \mathrm{mg} / 0.2 \mathrm{~mL} ; \mathrm{lysine}=2 \mathrm{mg} / 0.2 \mathrm{~mL} ; \mathrm{and}$ lysine $+\mathrm{methionine}=1+1 \mathrm{mg} / 0.2 \mathrm{~mL}$. cfu - colony-forming units; SEM - standard error of the mean. 
amniotic fluid increased ileum villi length of one-day-old broiler chicks. Also, we showed that low-dose lysine and methionine injections had no effect on gut microbiota. Consequently, both ileum histomorphological parameters and caecum total aerobic bacteria, as well as E. coli, Enterobactericaea, and coliforms were not affected since we used low-dose amino acid for in ovo nutrition.

In addition, statistical difference in bacteria colonization in caecum may be an indicator of microbial stress.

\section{Conclusions}

Low-dose $2 \mathrm{mg} / 0.2 \mathrm{~mL}$ in ovo injection of lysine can be used to increase hatchability.

\section{Acknowledgments}

This research project was fully sponsored by the Scientific Research Fund of Ahi Evran University (grant number PYO-ZRT.4003/2.13.001).

\section{References}

Al-Daraji, H. J.; Al-Mashadani, A. A.; Al-Hayani, W. K.; Al-Hassani, A. S. and Mirza, H. A. 2012. Effect of in ovo injection with L-arginine on productive and physiological traits of Japanese quail. South African Journal of Animal Science 42:139-145.

Al-Shamery, N. J. and Al-Shuhaib, M. B. S. 2015. Effect of in ovo injection of various nutrients on the hatchability, mortality ratio and weight of the broiler chickens. IOSR Journal of Agriculture and Veterinary Science 8:30-33.

Bhanja, S. K.; Mandal, A. B. and Goswami, T. K. 2004. Effect of in ovo injection of amino acids on growth, immune response, development of digestive organs and carcass yields of broilers. Indian Journal of Poultry Science 39:212-218.

Bhanja, S. K. and Mandal, A. B. 2005. Effect of in ovo injection of critical amino acids on pre- and post-hatch growth, immune competence and development of digestive organs in broiler chickens. Asian-Australasian Journal of Animal Sciences 18:524-531.

Bhanja, S. K.; Mandal, A. B.; Agarwal, S. K. and Majumdar, S. 2012. Modulation of post-hatch-growth and immunocompetence through in ovo injection of limiting amino acids in broiler chickens. Indian Journal of Animal Sciences 82:993-998.

Coskun, I.; Erener, G.; Sahin, A.; Karadavut, U.; Altop, A. and Okur, A. 2014. Impacts of in ovo feeding of dl-methionine on hatchability and chick weight. Turkish Journal of Agriculture Food Science and Technology 2:47-50.

Ebrahimnezhad, Y.; Salmanzadeh, M.; Aghdamshahryar, H.; Beheshti, R. and Rahimi, H. 2011. The effects of in ovo injection of glucose on characters of hatching and parameters of blood in broiler chickens. Annals of Biological Research 2:347-351.

Ebrahimi, M.; Janmohammadi, H.; Kia, H. D.; Moghaddam, G.; Rajabi, Z.; Rafat, S. A. and Javanmard, A. 2017. The effect of
L-lysine in ovo feeding on body weight characteristics and small intestine morphology in a day-old Ross broiler chicks. Revue de Medecine Veterinaire 168:116-125.

Ferket, P. R. 2006. Incubation and in ovo nutrition affects neonatal development. p.18-30. In: 33rd Annual Carolina Poultry Nutrition Conference, New York.

Ferket, P. R.; Uni, Z.; Tako, E.; Foye, O. T. and Oliveira, J. E. 2005. In ovo feeding nutrition: Impact on gene expression, gut development, and growth performance. p.160-172. In: The Annual Nutrition Conference. University of Arkansas, Rogers, AR.

Foye, O. T.; Uni, Z. and Ferket, P. R. 2006. Effect of in ovo feeding egg white protein, $\beta$-hydroxy- $\beta$-methylbutyrate, and carbohydrates on glycogen status and neonatal growth of turkeys. Poultry Science $85: 1185-1192$

Gaafar, K. M.; Selim, S. A. and El-ballal, S. S. 2013. Effect of in ovo administration with two levels of amino acids mixture on the performance of Muscovy ducks. Emirates Journal of Food and Agriculture 25:58-65.

Kadam, M. M.; Bhanja, S. K.; Mandal, A. B.; Thakur, R.; Vasan, P.; Bhattacharyya, A. and Tyagi, J. S. 2008. Effect of in ovo threonine supplementation on early growth, immunological responses and digestive enzyme activities in broiler chickens. British Poultry Science 49:736-741

Keralapurath, M. M.; Keirs, R. W.; Corzo, A.; Bennett, L. W.; Pulikanti, R. and Peebles, E. D. 2010. Effects of in ovo injection of L-carnitine on subsequent broiler chick tissue nutrient profiles. Poultry Science 89:335-341.

Khaligh, F.; Hassanabadi, A.; Nassiri-Moghaddam, H.; Golian, A. and Kalidari, G. A. 2017. Effects of in ovo injection of chrysin, quercetin and ascorbic acid on hatchability, somatic attributes, hepatic oxidative status and early post-hatch performance of broiler chicks. Journal of Animal Physiology and Animal Nutrition 102(1). https://doi.org/10.1111/jpn.12760

Ohta, Y.; Kidd, M. T. and Ishibashi, T. 2001. Embryo growth and amino acid concentration profiles of broiler breeder eggs, embryos, and chicks after in ovo administration of amino acids. Poultry Science 80:1430-1436.

Ohta, Y.; Tsushima, N.; Koide, K.; Kidd, M. T. and Ishibashi, T. 1999. Effect of amino acid injection in broiler breeder eggs on embryonic growth and hatchability of chicks. Poultry Science 78:1493-1498

Shafey, T. M.; Mahmoud, A. H.; Alsobayel, A. A. and Abouheif, M. A. 2014. Effects of in ovo administration of amino acids on hatchability and performance of meat chickens. South African Journal of Animal Science 44:123-130

Tako, E.; Ferket, P. R. and Uni, Z. 2004. Effects of in ovo feeding of carbohydrates and beta-hydroxy-beta-methylbutyrate on the development of chicken intestine. Poultry Science 83:2023-2028.

Tako, E.; Ferket, P. R. and Uni, Z. 2005. Changes in chicken intestinal zinc exporter mRNA expression and small intestine functionality following intra-amniotic zinc-methionine administration. Journal of Nutritional Biochemistry 16:339-346.

Uni, Z. and Ferket, P. R. 2004. Methods for early nutrition and their potential. World's Poultry Science Journal 60:101-111.

Uni, Z.; Tako, E.; Gal-Garber, O. and Sklan, D. 2003. Morphological, molecular and functional changes in the chicken small intestine of the late-term embryo. Poultry Science 82:1747-1754.

Zhai, W.; Gerard, P. D.; Pulikanti, R. and Peebles, E. D. 2011. Effects of in ovo injection of carbohydrates on embryonic metabolism, hatchability, and subsequent somatic characteristics of broiler hatchlings. Poultry Science 90:2134-2143. 